\title{
The characteristics of pulmonary tuberculosis amongst patients attending chest clinic, including age, sex, occupation and hemoglobin concentration in Benin City, Nigeria
}

\author{
F. A. Ehiaghe ${ }^{1 *}$, I. J. Ehiaghe ${ }^{2}$, S. T. Aladenika ${ }^{3}$, S. M. O. Etikerentse ${ }^{1}$, A. I. Ikusemoro ${ }^{1}$, \\ B. H. Oladehinde ${ }^{3}$, E. O. Osakue ${ }^{5}$, S. S. Enitan ${ }^{4}$, J. K. Fadairo ${ }^{6}$ \\ ${ }^{1}$ Department of Hematology, College of Health Sciences, Igbinedion University, Okada, Nigeria \\ ${ }^{2}$ Lahor Research Laboratory, Benin City, Nigeria \\ ${ }^{3}$ Department of Medical Microbiology, College of Health Sciences, Igbinedion University, Okada, Nigeria \\ ${ }^{4}$ Department of Physiology, College of Health Sciences, Igbinedion University, Okada, Nigeria \\ ${ }^{5}$ Chemical Pathology Department, Igbinedion University Teaching Hospital, Okada, Nigeria \\ ${ }^{6}$ Department of Medical Laboratory Science, Achievers University, Owo, Nigeria \\ Email: ${ }^{*}$ fredleo2547@yahoo.com
}

Received 29 October 2012; revised 30 November 2012; accepted 10 December 2012

\begin{abstract}
Aim: To study characteristics of pulmonary tuberculosis amongst patients attending chest clinics in Benin City. Materials and Methods: A total of 816 subjects comprising of $563(69 \%)$ males and $253(31 \%)$ females were enlisted for this study. Sputum specimen and blood were collected from all subjects. Acid alcohol fast bacilli from sputa were examined using the Ziehl Nelson staning technique. Hemoglobin concentration was determined using the method described by Dacis and Lewis. Result: Pulmonary tuberculosis infection was significantly affected by age among the male and female subjects studied $(P<0.05)$. Subjects within the age group of 21 - 30 years and 41 - 50 years had the highest risk of acquiring TB amongst the male and female population respectively. Although the unemployed subjects had the highest prevalence of TB (35\%), occupation did not significantly affect the prevalence of TB $(P>0.05)$. Irrespective of gender, anemia was significantly associated with pulmonary tuberculosis infection $(P<\mathbf{0 . 0 5})$. Conclusions: The prevalence of pulmonary tuberculosis $(37.4 \%)$ was significantly affected by age among male and female subjects. Anemia was associated with TB infection. Intervention effort at curbing the prevalence of TB and anemia is advocated.
\end{abstract}

Keywords: Tuberculosis; Anemia; Alcohol Acid Fast Bacilli (AAFB); Nigeria

*Corresponding author.

\section{INTRODUCTION}

Mycobacterium tuberculosis, the causative agent of $\mathrm{Tu}-$ berculosis (TB) has been presented in the human population since antiquity, fragments of the spinal column from Egyptian mummies from $2400 \mathrm{BC}$ show definite pathological signs of tubercular decay. The causative agent is transmitted exclusively by inhalation of infective droplet $(<5 \mathrm{~mm}$ across) from patients with open pulmonary tuberculosis through coughing or sneezing [1].

Nigeria is ranked 6th amongst the twenty two countries in the world known to be highly plagued by TB with about 259,000 cases annually and 113,000 being smear positive, In Nigeria, report from the Federal Ministry of Health in 2000 , revealed that the prevalence of TB range between $4 \%$ and $35 \%$ depending on the state. Oyo state recorded $4 \%$ while Abia and Kano state recorded $9 \%$, and $12 \%$, Kaduna state, $31 \%$ and Benue state $35 \%$. Reports from Edo state and other state in Nigeria are Limited. Among those initially infected, a small percentage $(5 \%$ to $10 \%)$ failed to control the disease. The majority of human infected with this organism mount an effective immune response that result in latent infection. However, reactivation of latent infection can occur in years to come in a small subset of infected persons, leading to active TB. Early immunologic and pathological events during the course of infection as well as other factors like malnutrition may influence the outcome of TB infection [2].

Anemia is defined by the World Health Organization as a hemoglobin concentration below the following thresholds, children $(5-12$ years $)<11.5 \mathrm{~g} / \mathrm{dl}$; teens $(12-15$ years) $<12.0 \mathrm{~g} / \mathrm{dl}$; Women $(>15$ years $)<12.0 \mathrm{~g} / \mathrm{dl}$; Men 
( $>15$ years $)<13.0 \mathrm{~g} / \mathrm{dl}$. However, it can denote decreased oxygen binding ability of each hemoglobin molecules due to deformity or lack in numerical development as in some types of hemoglobin deficiency. Generally, anemia in chronic disease like Tuberculosis is normocytic normochromatic type, although in a few cases, microcytosis and hypochromia also occurs [3-5].

Aim: To study the characteristics of pulmonary tuberculosis amongst patients attending chest clinics in Benin City.

\section{MATERIALS AND METHODS}

\section{Study Design}

A cross sectional Laboratory based analytical survey was adopted for this research.

\section{STUDY AREA}

This study was carried out in Benin City, Edo State, Nigeria. The two Hospitals used were Bethel Faith Medical Centre and Orobosa Medical Centre in Benin City.

\section{SUBJECTS}

The sample population consists of 816 subjects. 308 of patients who complaint of chest pain, cough, persistent fever and weight loss while the other 508 were age matched apparently healthy subject on routine checkup. Ethical approval and patient consent was obtained from the two centers.

\section{SELECTION AND EXCLUSION}

Both males and females will be included in this study.

A control group matched by age and sex will be selected from healthy subject on routine checkup.

Subjects diagnosed to with other systemic diseases other than TB will be excluded from this study.

TB patients already on drugs will also be excluded.

\section{SPUTUM}

Sputum specimen was collected in sterile, wide mouthed disposable containers. Three sputum specimens were obtained from each subject as recommended by the World Health Organization [6].

\section{SPUTUM PROCESSING}

Specimens were processed using the modification method described by Baltimore Biological Laboratories. Each sputum specimen was homogenized with an approximately equal volume of $40 \%(\mathrm{v} / \mathrm{v}) \mathrm{NaOH}$, containing phenol red indicator and the mixture digested for $15-20$ min at 37 . Subsequently, the mixture was neutralized with $2 \mathrm{~N} \mathrm{Hcl}$ and concentrated by centrifugation at $3000 \mathrm{rmp}$ for 5 min using a Gallenkamp bench centrifuge. The supernatant was discarded and the three smear of the deposit made, dried and heat fixed. Staining was by the Ziel-Neelsen (ZN) method. Stained slides were microscopically studied in about 100 fields before they could be ascertained for acid-fast bacillus (AFB) status [7].

\section{COLLECTION OF SAMPLES}

$5 \mathrm{ml}$ of blood venous blood was collected from the medial cubital vein using a vacutainer and needle from each of the subjects into an Ethylene Diamine tetra acetic acid (EDTA) container.

\section{BLOOD SAMPLE PROCESSING (THE CYANMETHAEMOGLOBIN METHOD)}

Sample preparation and test performance for Hemoglobin concentration were done using the method described by Dacis and Lewis [8]. $20 \mathrm{ul}$ of Blood is diluted in a 5 $\mathrm{ml}$ buffered solution of potassium cyanide to yield the stable hemoglobin derivative cyanmethemoglobin. The potassium ferricyanide converts the Haemoglobin to methaemoglobin which is further converted to cyanmethemoglobin by the action of potassium cyanide. This must be allowed to stand for at least three minutes, to allow for complete conversion of Hemoglobin to cyanmethemoglobin, before the absorbance is measured against a reagent blank at a wavelength of $540 \mathrm{~nm}$.

\section{STUDY DURATION}

Sample collection was from 6th of January 2009 to 20th of December 2010.

\section{DATA COLLECTION/STATISTICAL ANALYSIS}

Data was collected using self administered semi structure questionnaire. All numerical results were collated from the two groups. Data is presented as mean \pm Standard Deviation (S.D) and analyzed using one way analysis of variance (ANOVA).Using SPSS version 18.0. P values $\leq 0.05$ were considered significant.

\section{RESULTS}

Of the 816 subjects, $563(69 \%)$ were males and 253 $(31 \%)$ were females. The age group that has the highest number of subjects was those of $\geq 51$ (64.5\% of males and $34.5 \%$ of female), Table 1.

Positive AAFB cases were found to be highest amongst those of the age group $\geq 51$ (40\% of the males and $54.5 \%$ of the females). Closely followed by those of the age group $21-30$ and $41-50$, (50\% of the males and $20 \%$ of the females) and (40\% of the males and $18 \%$ of the fe- 
Table 1. Age and sex distribution of subjects.

\begin{tabular}{cccc}
\hline $\begin{array}{c}\text { Age Range } \\
\text { (Years) }\end{array}$ & Subjects & Males (\%) & Females (\%) \\
\hline$\leq 10$ & 6 & $3(50)$ & $3(50)$ \\
$11-20$ & 200 & $150(75)$ & $50(25)$ \\
$21-30$ & 120 & $80(66.7)$ & $40(33.3)$ \\
$31-40$ & 60 & $30(50)$ & $30(50)$ \\
$41-50$ & 120 & $100(83.3)$ & $20(16.7)$ \\
$\geq 51$ & 310 & $200(64.5)$ & $110(35.5)$ \\
Total & 816 & $563(69)$ & $253(31)$ \\
\hline
\end{tabular}

males) respectively. While those of the age group $\leq 10$ have No positive cases of AAFB, Table 2.

AAFB positive cases were found to be highest among the unemployed $35 \%$ of the population. It was closely followed by traders, farmers and students $(30 \%, 27.8 \%$ and $30 \%$ ) respectively with civil servant have the least positive cases of AAFB (25\%) of the population, Table 3.

The mean \pm S.D. of Hemoglobin concentration of males that are AAFB Positive were $11 \pm 0.04$ against the Negative AFFB males control $16 \pm 0.02$ shows a statistically significant decrease $(\mathrm{P}<0.05)$ and the mean \pm S.D. of Hemoglobin concentration of females with positive AAFB cases were $9 \pm 0.02$ against the Negative AAFB female control cases shows a statistically significant decrease $(\mathrm{P}<0.05)$, Table 4.

The mean \pm S.D. of Hemoglobin concentration of AAFB positive males of $11 \pm 0.04$ against the mean \pm S.D. of female positive AAFB of $9 \pm 0.02$ shows a statistically significant decrease $(\mathrm{P}<0.05)$, Table 4 .

\section{DISCUSSION}

The prevalence of pulmonary tuberculosis (TB) (37.4\%) was significantly affected by age among male and female subjects. The study revealed that subjects above fifty (50) years recorded a higher positive case of tuberculosis (TB) infection in both sexes. These might be due to the mode of spreading the infection which is via aerosolized droplets during coughing, sneezing and talking especially in poorly ventilated areas and the risk of the prolong exposure of the age group. This is in line with these findings. TB hinders socio-economic development, $75 \%$ of people with TB in the world are within the age $15-54$ years. In countries where TB has gone from high to low incidence, it is mainly a disease of older people [9]. Globally, the severe malnutrition and overcrowding facing children and older people caused a large increase in the risks of developing active TB due to its damaging effects on the immune system [10-14]. While those in the age group $\leq 10$ has no AAFB positive cases. These might be due to
Table 2. Distribution of AAFB positive and negative subjects according to age and sex with their percentage.

\begin{tabular}{ccccccc}
\hline $\begin{array}{c}\text { Age } \\
\text { Range } \\
\text { (Years) }\end{array}$ & $\begin{array}{c}\text { No. of } \\
\text { Male }\end{array}$ & $\begin{array}{c}\text { Positive } \\
(\%)\end{array}$ & $\begin{array}{c}\text { Negative } \\
(\%)\end{array}$ & $\begin{array}{c}\text { No. of } \\
\text { Female }\end{array}$ & $\begin{array}{c}\text { Positive } \\
(\%)\end{array}$ & $\begin{array}{c}\text { Negative } \\
(\%)\end{array}$ \\
\hline$\leq 10$ & 3 & $0(0)$ & $3(100)$ & 3 & $0(0)$ & $3(100)$ \\
$11-20$ & 150 & $10(6.7)$ & $140(93.3)$ & 50 & $5(10)$ & $45(90)$ \\
$21-30$ & 80 & $40(50)$ & $40(50)$ & 40 & $20(50)$ & $20(50)$ \\
$31-40$ & 30 & $10(33.3)$ & $20(66.7)$ & 30 & $25(83.3)$ & $5(16.7)$ \\
$41-50$ & 100 & $40(40)$ & $60(60)$ & 20 & $18(90)$ & $2(10)$ \\
$\geq 51$ & 200 & $80(40)$ & $120(60)$ & 110 & $60(54.5)$ & $50(45.5)$ \\
Total & 563 & $180(22.05) 383(46.93)$ & 253 & $128(15.68)$ & $125(15.31)$ \\
\hline
\end{tabular}

Table 3. Shows the occupational distribution of the AAFB positive subjects with their percentage.

\begin{tabular}{ccc}
\hline Occupation & No. of Subjects & Positive Cases (\%) \\
\hline Students & 100 & $30(30)$ \\
Farmers & 180 & $50(27.8)$ \\
Unemployed & 286 & $100(35)$ \\
Traders & 200 & $60(30)$ \\
Civil Servant & 20 & $5(25)$ \\
Others & 30 & $5(16.7)$ \\
Total & 816 & $250(30.6)$ \\
\hline
\end{tabular}

intensive and compulsory $\mathrm{TB}$ vaccination programmes for children currenting going on in Benin City in particular and Nigeria in General, which is in line with these findings. Many country use Bacillus Calmette Guerin (BCG) vaccine as part of their TB control programmes, especially for children, and BCG provides protection against severe forms of pediatric TB, but has been shown to be unreliable against adult pulmonary $\mathrm{TB}$, which account for the disease burden worldwide $[15,16]$.

AAFB positive cases were found to be the highest among the unemployed $(35 \%)$ of the population, closely followed by traders $(30 \%)$ of the population and next by farmers $27.8 \%$ of the population. This group of subjects falls under the low income earner. Majority of them may be poor and might not be able to afford the renting of appropriate accommodation. Consequently, they hire low-cost poorly ventilated and overcrowded rooms, giving room to $\mathrm{M}$. tuberculosis transmission from infected individuals; this is in agreement with these findings, the risk of developing TB increases considerably when $\mathrm{TB}$ infection co-exists with as alteration in the immune system, such as malnutrition and overcrowding of the subjects [17]. Tuberculosis is a major cause of morbidity and mortality worldwide and is spread primarily via 
Table 4. Shows the mean \pm S.D. of hemoglobin concentration of positive and negative AAFB subjects.

\begin{tabular}{|c|c|c|c|c|c|}
\hline Subjects & $\begin{array}{l}\text { Positive } \\
\text { AAFB }\end{array}$ & $\begin{array}{l}\text { Mean } \pm \text { S.D. } \\
(\mathrm{g} / \mathrm{dl})\end{array}$ & $\begin{array}{l}\text { Negative } \\
\text { AAFB }\end{array}$ & $\begin{array}{c}\text { Mean } \pm \text { S.D. } \\
(\mathrm{g} / \mathrm{dl})\end{array}$ & P Values \\
\hline Males & & $11 \pm 0.04$ & & $16 \pm 0.02$ & $<0.05$ \\
\hline \multirow[t]{2}{*}{ Females } & & $9 \pm 0.02$ & & $14 \pm 0.01$ & $<0.05$ \\
\hline & & $<0.05$ & & & P Values \\
\hline
\end{tabular}

Keys: Data are presented as mean \pm Standard Deviation (S.D.) and analyzed using one way analysis of variance (ANOVA). Using SPSS version 18.0. P values $\leq 0.05$ were considered significant.

aerosolized droplets during coughing and sneezing especially in poorly ventilated areas. The factors contributing to the resurgence of TB includes inadequate treatment, poverty, malnutrition, overcrowding and increased numbers of displaced persons [18].

At diagnosis the mean hemoglobin concentrations were $11.0 \mathrm{~g} / \mathrm{dl}$ for males and $10.0 \mathrm{~g} / \mathrm{dl}$ for the females AAFB positive patients shows a statistically significant decrease than the mean values for healthy males and females control subjects $16.0 \mathrm{~g} / \mathrm{dl}$ and $14 \mathrm{~g} / \mathrm{dl}(\mathrm{P}<0.05)$ respectively. These might be due to oxidative damage to the red blood cells arising from an imbalance between reactive oxygen species production and antioxidant level occasioned by TB infection. It has been earlier reported that subnormal hemoglobin concentration occurring in TB patients is due to the underlying chronic inflammatory process causing anemia by cytokines production [19]. Factors such as decreased in red cell survival and reduced erythropoietin response by the bone marrow erythroid cells can induce anemia $[19,20]$.

It was observed that females are likely to develop anemia when infected with AAFB. These might be due to the normal monthly menstrual blood lost by the female subjects' couple with malnutrition facing the women folks in the average Nigeria setting. This agrees with these findings. A mild anemia was observed in $45 \%$ female AAFB positive subjects. However, the anemia was due to inflammation as well as that of iron deficiency [21].

Conclusively, the prevalence of pulmonary tuberculosis $(37.4 \%)$ was significantly affected by age among male and female subjects. Anemia was associated with TB infection. Intervention effort at curbing the prevalence of TB and anemia is advocated.

\section{REFERENCES}

[1] Johnston, R.E. and Wildrick, K.H. (1974) State of the art review. The impact of chemotherapy on the care of patiets with tuberculosis. American Review of Respiratory Disease, 109, 636-664.

[2] Federal Ministry of Health (FMH) (2000) Tuberculosis and leprosy control effects in Nigeria National Tubercu- losis and leprosy control programme. Infection and Immunity, 70, 3222-5327.

[3] World Health Organization (2008) Worldwide prevalence of anemia. WHO, Geneva.

[4] Al-Omar, I.A., Al-Ashban, R.M. and Shah, A.H. (2009) Hematological abnormalities in Saudis suffering from pulmonary Tuberculosis and their response to the treatment. Research Journal of Pharmacology, 4, 78-85.

[5] Makenna, N.A. (1992) Dangerous liaison: Tuberculosis and HIV. World AIDS, 23, 5-7.

[6] World Health Organization (2006) Treatment of tuberculosis: Guidelines for National Programme. World Health Organization, Geneva.

[7] Baltimore Biological Laboratories (BBL) (2001) Detection and sensitivity testing of Mycobacterium tuberculosis and other mycobacterium. In: Rhode, P.A., Ed., BBL Manual of Products and Laboratory Procedures. 5th Edition, Baltimore, 33-34.

[8] Dacis, J. and Lewis, O. (2006) Practical Hematology. 8th Edition, Churchill Livingstone, London, 27-30.

[9] Corbett, S.A., Reba, S.M., Martin, T.D. and Boo, W.H. (2002) Neutrophil mediated mycobacterial immunity in the lung during Mycobacterium bovis BCG infection in mice. Infection and Immunity, 70, 5322-5327. doi:10.1128/IAI.70.9.5322-5327.2002

[10] Schaible, U.E. and Kaufmann, S.H. (2007) Malnutrition and infection, complex mechanisms and global impacts. Seminars in Respiratory and Critical Care Medicine Journal, 5, 115-120.

[11] Lonnroth, K. and Raviglione, M. (2008) Global epidemiology of tuberculosis, prospects for control. Seminars in Respiratory and Critical Care Medicine Journal, 5, 481491.

[12] Davies, P.D. (2003) The World wide increase in tuberculosis, how demographic changes, HIV infection and increasing numbers in poverty are increasing tuberculosis. Annals of Medicine, 4, 235-243. doi: $10.1080 / 07853890310005713$

[13] Spence, D.P., Hotchikiss, J., Williams, C.S. and Davies, P.D. (1993) Tuberculosis and poverty. British Medical Journal, 63, 757-761.

[14] Skeiky, Y.A. and Sadoff, J.C. (2006) Advances in tuberculosis vaccine strategies. Nature, 6, 469-476.

[15] Webber, D. and Kremer, M. (2001) Stimulating industrial $\mathrm{R} \& \mathrm{D}$ for neglected infectious diseases, economic perspectives. Health, 8, 693-801.

[16] Hamburg, M.A. and Freiden, T.R. (2001) Tuberculosis transmission in the 1990's. The New England Journal of Medicine, 330, 1750-1751. doi:10.1056/NEJM199406163302410

[17] Monica, C. (2000) District laboratory practice in tropical countries part 2. Cambridge University Press, Cambridge, 207-266.

[18] Lee, S.W., Kang, Y.A., Yoon. Y.S., VM, S.W., Lee, S.M., Yoo, C.G., Kim, Y.W., Han S.K., Shin, Y.S. and Yim, J.J. (2006) The prevalence and evaluation of anemia associated with tuberculosis. Journal of Korean Medical Sci- 
ence, 6, 1028-1032. doi:10.3346/jkms.2006.21.6.1028

[19] Ebrahim, O., Folb, P.I. and Robson J.P. (1995) Blunted erythropoietin response to anemia in tuberculosis. European Journal of Haematology, 55, 251-254. doi:10.1111/j.1600-0609.1995.tb00267.x

[20] Miah, M.A., Chowdhury, U.A., Ahmed, N., Shafique, M. and Islam, N. (2007) Simultaneous occurrence of multi- ple types of cutaneous tuberculosis (TVC and PNT) with internal organ tuberculosis (PTB). Seminars in Respiratory and Critical Care Medicine Journal, 1, 108-112.

[21] Das, B.U., Devi, U, Mohan, R.C., Srivastava, V.K., Rath, P.K. and Das, B.S. (2003) Effects of iron supplementation on mild to moderate anemia in pulmonary tuberculosis. British Journal of Nutrition, 3, 541-550. 